\title{
Guest editorial: chronic myeloid leukemia
}

\author{
Yosuke Minami ${ }^{1}$
}

Received: 20 August 2018 / Accepted: 21 August 2018 / Published online: 28 August 2018

(c) The Japanese Society of Hematology 2018

The emergence of resistance to molecular target therapies such as ABL-kinase inhibitors in chronic myeloid leukemia (CML) has become a significant problem despite remarkable and successful clinical aspects with treatment-free remission (TFR) [1]. In this issue, Dr. D. Rea and Dr. J.-M. Cayuela summarize clinical results and current issues regarding TFR in patients with CML [2]. The most common cause of resistance in CML is supposed to be the selection of leukemic clones with point mutations in the ABL-kinase domain, and overexpression of target molecules is another reason of resistance [3].

Comprehensive genetic analyses have shaped a deeper understanding of hematologic malignancies. It is also becoming clear that cancer cells display features of normal tissue organization in the microenvironment, where cancer stem cells (CSCs) can drive tumor growth in the tumor environment. It has been proposed that the genetic and CSC models of cancer can be harmonized by considering the role of genetic diversity and tumor heterogeneity $[4,5]$. Each clone contains a mixture of cells that vary with respect to their stemness and/or proliferative ability. Standard chemotherapy can reduce tumor burden by eliminating the highly proliferative cells within each subclone, while sparing the relatively dormant cells; following therapy, these cells can seed a renewed cancer. Subclonal diversity can be altered with chemotherapy and can allow for the selection of cells with additional genetic mutations that confer a survival advantage [6]. The concept of leukemia stem cells (LSCs) also becomes critical in understanding the pathogenesis of leukemia. In 1990s, Dick et al. showed that the $\mathrm{CD} 34^{+} \mathrm{CD} 38^{-}$population in bone marrow cells from acute myelogenous leukemia (AML) patients can reconstitute

Yosuke Minami

yominami@east.ncc.go.jp

1 Department of Hematology, National Cancer Center Hospital East, 6-5-1 Kashiwanoha, Kashiwa 277-8577, Japan human AML in immunodeficient mice, demonstrating clear evidence for the presence of LSCs [7, 8]. Xenogeneic transplantation of leukemia cells into immunodeficient mice has made it possible to identify cell fractions enriched for LSCs, and to characterize an LSC-specific gene expression signature that is strongly correlated with patient survival following standard chemotherapy [9]. There have been steady improvements to the xenograft assay, including development of more immune-deficient recipient mice, better methods for transplantation, and humanizing recipients with human tumor environment and/or growth factors [10].

Persistent disease, especially retention of LSCs, is another therapeutic challenge also in CML. Novel anti-metabolic signal agents and allosteric inhibitors such as Asciminib are under research \& development for overcoming resistance and disease persistence [11-13]. In this issue, Dr A Inoue et al. describe the cutting-edge research progress regarding CML stem cells and the further clinical possibilities [14].

\section{References}

1. Takahashi N, Tauchi T, et al. Deeper molecular response is an independent predictive factor for successful treatment-free remission after imatinib discontinuation in patients with chronic-phase chronic myeloid leukemia: JALSG-STIM213 Study. Int J Hematol. 2018;107:185-93.

2. Rea D, Cayula J-M. Treatment-free remission in patients with chronic myeloid leukemia. Int J Hematol. 2018; https://doi. org/10.1007/s12185-017-2295-0.

3. Ami B, Patel T, O'Hare, Deininger MW. Mechanisms of resistance to ABL kinase inhibition in chronic myeloid leukemia and the development of next generation ABL kinase inhibitors. Hematol Oncol Clin N Am. 2017;31:589-612.

4. Shackleton M, Quintana E, et al. Heterogeneity in cancer: cancer stem cells versus clonal evolution. Cell. 2009;138:822-9.

5. Kreso A, Dick JE. Evolution of the cancer stem cell model. Cell Stem Cell. 2014;14:275-91.

6. Ding L, Ley TJ, et al. Clonal evolution in relapsed acute myeloid leukaemia revealed by whole-genome sequencing. Nature. 2012;481:506-10. 
7. Lapidot T, Sirard C, et al. A cell initiating human acute myeloid leukaemia after transplantation into SCID mice. Nature. 1994;367:645-8.

8. Bonnet D, Dick JE. Human acute myeloid leukemia is organized as a hierarchy that originates from a primitive hematopoietic cell. Nat Med. 1997;3:730-7.

9. Eppert K, Takenaka K, et al. Stem cell gene expression programs influence clinical outcome in human leukemia. Nat Med. 2011;17:1086-93.

10. Rongvaux A, Takizawa H, Strowig T, Willinger T, Eynon EE, Flavell RA, Manz MG. Human hemato-lymphoid system mice: current use and future potential for medicine. Annu Rev Immunol. 2013;31:635-74.
11. Prost S, Relouzat F, Spentchian M, Ouzegdouh Y, Saliba J, Massonnet $\mathrm{G}$, et al. Erosion of the chronic myeloid leukaemia stem cell pool by PPAR $\gamma$ agonists. Nature. 2015;525:380-3.

12. Zhang J, Adrián FJ, Jahnke W, Cowan-Jacob SW, Li AG, Iacob $\mathrm{RE}$, et al. Targeting Bcr-Abl by combining allosteric with ATPbinding-site inhibitors. Nature. 2010;463:501-6.

13. Wylie AA, Schoepfer J, Jahnke W, Cowan-Jacob SW, Loo A, Furet $\mathrm{P}$, et al. The allosteric inhibitor ABL001 enables dual targeting of BCR-ABL1. Nature. 2017;543:733-7.

14. Inoue A, Kobayashi CI, et al. Chronic myeloid leukemia stem cells and molecular target therapies forovercoming resistance and disease persistence. Int J Hematol. 2018; . https://doi.org/10.1007/ s12185-018-2519. 